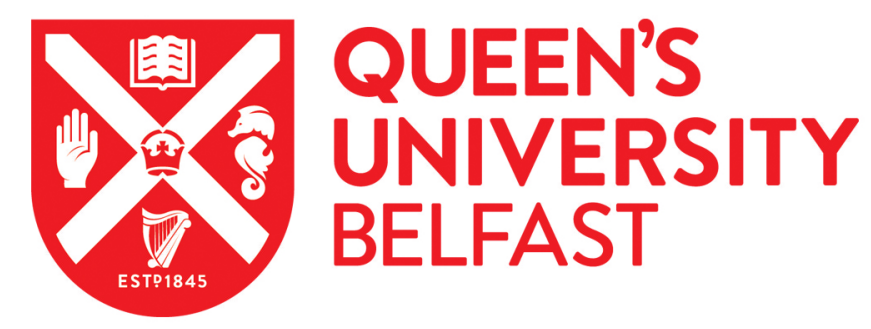

\title{
Feasibility, normative heuristics and the proper place of historical responsibility - a reply to Ohndorf et al.
}

Schuppert, F., \& Seidel, C. (2017). Feasibility, normative heuristics and the proper place of historical responsibility - a reply to Ohndorf et al. Climatic Change, 140(2), 101-107. https://doi.org/10.1007/s10584-016$1861-4$

Published in:

Climatic Change

Document Version:

Peer reviewed version

Queen's University Belfast - Research Portal:

Link to publication record in Queen's University Belfast Research Portal

Publisher rights

(C) 2016 Springer Science+Business Media Dordrecht 2016

The final publication is available at Springer via http://dx.doi.org/10.1007/s10584-016-1861-4

This work is made available online in accordance with the publisher's policies.

\section{General rights}

Copyright for the publications made accessible via the Queen's University Belfast Research Portal is retained by the author(s) and / or other copyright owners and it is a condition of accessing these publications that users recognise and abide by the legal requirements associated with these rights.

Take down policy

The Research Portal is Queen's institutional repository that provides access to Queen's research output. Every effort has been made to ensure that content in the Research Portal does not infringe any person's rights, or applicable UK laws. If you discover content in the Research Portal that you believe breaches copyright or violates any law, please contact openaccess@qub.ac.uk. 


\section{Feasibility, normative heuristics and the proper place of historical responsibility - a reply to Ohndorf et al.}

\footnotetext{
Abstract: In this comment, we pick up three points raised by Ohndorf et al. (2015) in their reply to our ethical assessment of the German Advisory Council's Budget Approach (WBGUBA). First, we discuss and clarify the relationship between ethics and political feasibility, highlighting that the way Ohndorf et el. use feasibility creates an unwarranted status quo bias. Second, we explain the proper place historical responsibility should have within the WBGUBA, stressing the fact that the reasons why we choose one policy proposal over another matter. Third, we analyze the limited extent to which a normative heuristic should motivate an ethically ambitious policy proposal like the WBGUBA.
} 


\section{Introduction}

In their insightful reply, Ohndorf et al. (2015) make a range of critical observations, from the viewpoint of environmental economics, regarding the validity and applicability of our ethical assessment of the German Advisory Council’s Budget Approach (WBGUBA). In this paper, we examine some of Ohndorf et al.'s claims, focusing on the relationship between ethics and political feasibility, the proper place of historical responsibility, and the function of normative heuristics. Our aim is twofold: we want to clarify some of the issues discussed in our original paper so as to avoid misunderstandings, and we want to highlight how misconstruing the relationship between ethics and political feasibility leads to a problematic status quo bias.

\section{The relationship between ethics and political feasibility: avoiding a status quo}

bias

The WBGUBA is a burden sharing approach, aiming to come up with a distribution of the burdens associated with timely and effective climate mitigation. Of course we agree with Ohndorf et al. (2015: 386) that some ways of distributing the burdens of climate mitigation might be 'considered to be more just and/or politically feasible than others'. But Ohndorf et al. also claim that apart from any future climate agreement having to be 'strict enough to considerably mitigate climate change', the distribution of burdens must be 'perceived as "fair" and, most importantly, acceptable to all players' (2015: 387; emphasis added). While it is indeed true that any proposal will only be agreed upon if all parties can (on some level and for some reason) accept it, it is important to be clear about what the relationship between ethics and political feasibility is so as to avoid falling into an unwarranted status quo bias. With regard to the arguments presented by Ohndorf et al. we want to raise two main issues: first, the point at which ethics enters a political process (A); second, the way that political feasibility can be misused to narrow the political playing field and to thereby introduce a status quo bias (B).

(A) First of all, in their response Ohndorf et al. (2015: 387-9) move from discussing the WBGUBA as a policy proposal to discussing agreements as outcomes of political bargaining This is a big shift since the WBGUBA explicitly aspires to being an ethically justifiable and politically acceptable policy proposal (see e.g. WBGU 2009: 2), while political bargaining processes often lack that kind of commitment. There is a distinct difference between a policy proposal (whose ethical credentials are fed into a political process) and the actual bargaining process as such (which might well be understood as a mere power game). Thus, while Ohndorf et al. (2015: 387) talk about actual 
political agreements and hence situations of bargaining when stating that all that matters is that the outcome is 'perceived as “fair” and, most importantly, acceptable to all players' (emphasis added), these suggestions and observations have little traction when it comes to discussing the WBGUBA understood as a policy proposal which sees as one of its explicit strong points its ethical credentials in terms of actual rather than perceived fairness.

Second, Ohndorf et al. (2015: 388) make the assumption that the distribution of the remaining carbon budget is 'either a question of justice considerations, or a subject of political bargaining'. This, however, seems to get things wrong: political bargaining is a process that comes at the end and during this process a whole range of arguments will be considered, including ethical (which include justice-based considerations) and economic arguments. To suggest that bargaining can crowd out ethics and turn ethical considerations into an unnecessary luxury is to draw a skewed picture of what kind of process political bargaining is. Political bargaining processes rely on proposals and arguments having fed into the process at an earlier stage. In these proposals and arguments, ethical considerations should play an important role (even if it is unclear how strongly they resonate during the actual negotiation process). However, if the actual COP negotiations show one thing quite clearly, then that ethical considerations do in fact play such an important role in arguing for or against alternative proposals. Thus, to suggest that bargaining excludes ethical considerations would be misleading.

(B) The main issue we tried to highlight in our original article (Schuppert and Seidel 2015), though, and which Ohndorf et al. seem to have somewhat misread is how the WBGUBA actually trades off ethical considerations for political feasibility, without a) making this trade off as explicit as necessary and b) realizing that political feasibility should be seen as a malleable variable, not a fixed parameter.- The way (the WBGUBA and) Ohndorf et al. approach political feasibility has two distinctive features: First, feasibility is essentially regarded as binary political acceptability (i.e. that people would vote for a proposal or that leaders would adopt a proposal) and acts as a threshold parameter, which proposals must pass in order to be worthy of discussion - either an option is (sufficiently) feasible and thus on the table, or it is not. Second, Ohndorf et al. seem to hold that no matter whether an option is feasible or not, its feasibility is somewhat fixed and not subject to (foreseeable) change. Both features are problematic: Of course, in one sense, 'feasibility' is a binary concept - if we understand it similar to 'possibility', then any proposal with a non-zero probability of being adopted is feasible. ${ }^{1}$ But this is not the sense in which Ohndorf et al. understand feasibility

1 Note that from a strictly mathematical point of view, even events with zero probability might be possible (e.g. the probability that a real number randomly chosen from the interval $[0,1]$ is precisely 0.436791 is exactly 0 , although

Commented [Christian1]: Domninic asked for evidence., ife easiliy available. Any idea? (not very important) KOENNEN WIR UEBERGEHEN, FINDE ICH. Ich habe dazu Aufsaetze, aber das wuerde viele Worte kosten, da man um diesen Punkt zu belegen schon mehr als eine Studie anfuehren muss.. 
constraints. For instance, they rule out the immediate stoppage of all GHG emissions from further consideration for the reason that this option is not politically acceptable (Ohndorf et al. 2015: 391), but arguably, it is not metaphysically impossible that even the most ambitious climate policy is adopted - it just is very unlikely, given voters' and policy makers' present preferences, motives and beliefs. So both WBGUBA and Ohndorf et al. use feasibility constraints to draw a strict line within the range of options with a non-zero probability of being adopted: some proposals, though possible (and thus feasible in the first sense) are ruled as too unrealistic or unlikely (and thus infeasible in another sense) - given voters’ and policy makers' present attitudes. But as the intensifier “too" indicates, this account treats political feasibility, at the bottom, as a gradual rather than a binary concept: Within the set of possible options, some are more 'realistic' or more 'feasible' than others in the sense that politicians are more or less likely to be agree on them or voters are more or less likely to vote for them, and an option is too unlikely or unrealistic, if it falls below a certain threshold. By introducing this threshold, a new binary notion of feasibility has been generated, since the threshold separates the (newly) 'feasible' from the (newly) 'infeasible' options. And only on the basis of this (binary) threshold conception of feasibility is it possible to rule out certain possible but unlikely proposals on grounds of being 'infeasible'. Now, we do not want to raise the issue of how difficult it is to justify the threshold. Our point is rather that where, exactly, the line is drawn depends on an contingent fact(more or less) controversial assumptions about voters' and policy makers' attitudes - what their given present preferences, motives and beliefs are - making the newly introduced threshold a socio-political choice, not an immutable fact. And these attitudes can and do change. More often than not, attitudes change for particular reasons, including ethical reasons. Therefore, using political feasibility as a binary concept to determine which options will be at all discussed in the public domain without attending to the fact that its binary structure is an artifact of introducing a threshold that is relative to given but changeable attitudes introduces an unwarranted status quo bias.

\section{In contrast to the WBGUBA's and Ohndorf et al.'s terms approach of conceiving feasibility is nothing more than political acceptability, i.e. that people would vote for a proposal or that leaders are likely to adopt a proposal. For Ohndorf et al. feasibility is as a binary concept, something is either feasible (i.e. likely to be voted for) or not. However, political feasibility is of courseshould father be understood as a gradual concept in the sense that any policy option that has a non zero-} probability is somewhat feasible (which means that it is at all possible for this option to come about). It is within this realm of options with a non-zero probability that we commonly introduce a

this event is clearly possible - it can occur). So even proposals with zero probability of being adopted might be "feasible" in the sense of "possible".

Commented [A2]: Nein. Das hat mich facts wenig zu tun. Es is eine Annahme, die besser oder schlechter gerechtfertigt sein kann. Mir waere es hier schon wichtige die sozio-politische Natur des
thresholds rauszustellen. Koenntest Du Dich damit anfreunden? 
socio-politically constructed threshold which separates the options we deem feasible (or 'realistic') from those we hold to be infeasible (or 'unfealistic'). However, the introduction of the threshold is at socio political choice and by pretending that the threshold is fixed and immovable we naturalize an antificial political distinction. Policy makers faces a wide spectrum of options with some being more feasible than others, in the sense that it is more likely than not that people vote for the proposal in question or that a given leader will embrace said option. What is important here is that voters' and leaders' attitudes can and do change. More often than not, attitudes change for particular reasons, including ethical reasons. Therefore, to use political feasibility as a trump which already determines which options will be at all diseussed in the public domain means to introduce an mawarranted status quo bias.

While political feasibility of course matters and while it is in a case like climate change prudent to think about how one can square the circle of finding an ethically just and politically acceptable solution, subjugating the ethical to the feasible is unjustified and potentially dangerous. Imagine a slave holder society in which slaves are not only excluded from the political process but also treated very badly. In such a society any proposal for abolishing slavery might be considered utterly unfeasible. But is this really a good normative reason not even to table such proposals? We don't think so. The ethical analysis of what is at stake needs to come first and only once we know what is right and what is wrong can we worry about the issue of how likely it is that the right option will be chosen if things were put to a vote. Moreover, to narrow the parameters of the political debate based on an immutable understanding of what is politically feasible does not only curtail political imagination, it also tips the scales towards preservation of the political status quo. This is precisely what seems to happen when the WBGUBA trades off the ethical aspect of historical responsibility (which based on the WBGU's calculations would lead to immediate carbon bankruptcy for some states) for political feasibility, which suggests that historical over-emitters must be allowed to continue emitting (at reduced levels). In many cases, trade offs between ethical justifiability and political feasibility will be unavoidable. But to restrict one's view in the name of political feasibility from the get-go is to deprive oneself of doing as well as one can, and to mask the fact that one engages in said trade offs is to hide from others valuable information about the normative losses one incurs by going for what is deemed feasible.

\section{The proper place of historical responsibility}

With regard to the proper place of historical responsibility Ohndorf et al. (2015: 389f.) respond to our initial argument that the WBGU allocates emission rights "with too little regard for both, past 
injustices and overconsumption” (Schuppert and Seidel 2015: 401) by pointing out that the emission allocation which results from WBGU's equal per-capita approach (given constant 2008 per-capita levels) "places a relatively heavy burden on industrialized countries and makes some of these countries “carbon-bankrupt” after only a few years, whereas 'poorer' countries with low historical emissions continue to dispose of spare budget in the year 2050” (2015: 390). This, Ohndorf et al. suggest, is in line with the polluter pays principle rather than showing 'too little regard for past injustices and overconsumption', as we have claimed.

But this reply misunderstands our argument. We agree that to assess whether a distributive principle (such as WBGUBA) is in line with historical responsibility, we have look at the burdens induced by that principle and see how well burdens correspond to contributions to the problem (i.e. past emissions) - this is a necessary criterion of conformity with the polluter pays principle. But the burdens for agent $\mathrm{P}$ are a function of two variables: the initial emission permits allocated to $\mathrm{P}$ and P's transformation rate (i.e. how a reduction in P's emissions translates into additional burdens for P). AndIn addition, we argue that, from an ethical point of view, differences in contributions to the problem (i.e. differences in past emissions) ought to be reflected in the initial allocation of emissions rights as well (and not only in the burdens induced). Since allocating on an equal percapita basis disregards these differences, it is (to some extent) unjust - even if the transformation rates happen to be such that the resulting allocation of burdens corresponds to past emissions. So our claim about the proper place of past injustice (or historical responsibility) is "input-sensitive” in sense that the extent to which past injustice is reflected in the initial allocation of emission rights matters. By contrast, Ohndorf et al.'s claim is "input-insensitive" in sense that it is exclusively concerned with the relation between past missions and the burdens induced by the WBGUBA; (where these burdens are measured in terms of reach ofof the lifetime of the allocated budget, i.e. remaining time until carbon bankruptcy on an equal per-capita rule). On their account, historic responsibility is adequately taken into account if the burdens resulting from the initial allocation reflect differences in contributions to the problem, irrespective of whether these differences are also reflected in the initial allocation. Ohndorf et al. thus take the correspondence between burdens and past emissions as a sufficient criterion of conformity with the polluter pays principle.

To illustrate the difference between input-sensitive and input-insensitive approaches, consider the following analogy: A twelve-piece-cake is to be shared among four kids, but two of them have secretly eaten up two thirds of it. What would be a fair allocation of the remaining four pieces among all four kids? The input-sensitive approach claims (i) that it is unfair to give each child one piece, because this disregards differences in the children's contribution to the problem (the scarcity of the remaining cake and the associated harms of cake deprivation and frustrated expectations) at

Formatted

Commented [Christian3]: Dominic hatte angemerkt, dass „reach“ für ihn unüblich sei. Ohndorf et al. verwenden „reach of budget lifetime" in ihrer Tabelle, in der zugehörigen caption heißt es aber "coverage“. Du bist fast native: Wie drückt man „Reichweite“ in diesem Kontext am besten aus? Wenn coverage (oder ein anderer Begriff) besser ist, könntest Du dann global ersetzen? Vielen Dank! ICH FINDE REACH OKAY. ALS EINZIGE ALTERNATIVE FINDE ICH LIFETIME OKAY, was der Vorschlag meines native speaker Kollegen war und ja auch bei Ohndorf vorkommt. 
the level of the initial allocation, and (ii) that we ought to give the gluttons fewer of the remaining pieces. By contrast, on an input-insensitive approach exclusively concerned with the „reach of the cake budget“, an equal per-capita allocation is not necessarily unfair if the two gluttons have higher “cake consumption rates" and run "cake bankrupt” sooner than the other kids, because in this case the burdens induced - "cake deprivation” - would indeed reflect differences in the children's contribution to the problem.

To us, it seems evident that the input-sensitive approach is superior in the cake case. Here are two arguments why, from an ethical point of view, an input-sensitive approach to historical responsibility is also preferable in the case of climate change. First, the input-sensitive approach is required to avoid counter-intuitive ethical implications in certain cases. This is because the burdens induced by an allocation are a function of a factor which is not essentially linked to historical responsibility, viz. the present per-capita emission level: Other things (in particular: historical responsibility) being equal, higher present per-capita emissions imply shorter reach of the allocated budget. But although present per-capita emission levels are often tightly correlated with historical responsibility (in terms of past emissions), this is not necessarily so. As a consequence, the required correspondence between burdens induced and historic emissions does not hold if we compare emitters with high past, but low present per-capita levels, to emitters with low past, but high present per-capita levels. Consider the following set of examples with two equally populated countries, A and $B$ (see table 1). Case I illustrates the burdens induced by WBGUBA under the assumption of Ohndorf et al.; everything seems fine, since the country with high responsibility (A) runs out of permits sooner than the country with low responsibility (B). But this is so only because in Case I, historical responsibility is highly correlated with current emissions. If, as in Case II, past high polluters are present low polluters, the correspondence between responsibility and burdens breaks down.

\begin{tabular}{lcccc}
\hline CASE I & $\begin{array}{c}\text { historical } \\
\text { responsibility }\end{array}$ & $\begin{array}{c}\text { initial } \\
\text { permits }\end{array}$ & $\begin{array}{c}\text { current } \\
\text { emissions/a }\end{array}$ & $\begin{array}{c}\text { reach of } \\
\text { budget (a) }\end{array}$ \\
\hline country A & high & 50 & 25 & 2 \\
country B & low & 50 & 10 & 5 \\
\hline CASE II & & & & \\
\hline country A & high & 50 & 10 & 5 \\
country B & low & 50 & 25 & 2 \\
\hline CASE III & & & & \\
\hline
\end{tabular}

Commented [Christian4]: Dominic hat vorgeschlagen, dass wir für $\mathrm{A}$ und $\mathrm{B}$ hier konkrete Staaten benennen. Ich habe mir ein paar Zahlen angeschaut, und welche Länder man hier empirisch adäquat einsetzt, hängt sehr stark davon ab, welchen Zeitraum genau man bei historic responsibility betrachtet und ob man bei historic responsibility auch absolute emissions einbezieht. Ich denke, dass wir uns mit einem konkreten Beispiel nur unnötig angreifbar machen. Wir machen einen grundsätzlichen Punkt. GUT. Hast RECHT. MACHEN WIR SO 


\begin{tabular}{ccccc}
\hline CASE I & $\begin{array}{c}\text { historical } \\
\text { responsibility }\end{array}$ & $\begin{array}{c}\text { initial } \\
\text { permits }\end{array}$ & $\begin{array}{c}\text { current } \\
\text { emissions/a }\end{array}$ & $\begin{array}{c}\text { reach of } \\
\text { budget (a) }\end{array}$ \\
\hline country A & high & 25 & 25 & 1 \\
country B & low & 75 & 10 & 7.5 \\
\hline CASE IV & & & & \\
\hline country A & high & 25 & 10 & 2.5 \\
country B & low & 75 & 25 & 3 \\
\hline
\end{tabular}

Table 1 Set of examples with two equally populated countries.

As Cases III and IV illustrate, this is not (or less likely) so, if historical responsibility is taken into account at the level of the initial allocation, such that high past emitters receive fewer initial permits: comparing induced burdens within the same current emissions scenarios (i.e. comparing Case I with Case III and Case II with Case IV), we see that the burdens induced correspond to historical responsibility (although to different degrees) in both input-sensitive approaches. So just as with the gluttonous kids, departing from an equal per-capita allocation is the more robust way to bring the burdens induced in line with historical responsibility.

A second argument for the input-sensitive approach is this: It usually makes a moral difference whether we take a morally relevant factor explicitly into account when we distribute something or whether, accidentally, the distribution happens to coincide with what the morally relevant factor suggests. Suppose that because she cares for the two gluttons' health, the mother indeed gives fewer of the remaining four pieces to the two gluttons and more to the other two kids. Then although accidentally, she distributes in accordance with what correcting past injustice requires, she does the right thing for the wrong reason, since she does not take the past injustice into account in her deliberation. The two other kids could - rather precociously but rightly - complain that they have been wronged by having been deprived of their fair share (of three pieces), and that this wrong is not acknowledged unless their mother grounds her distribution upon this particular consideration. This suggests that ethically speaking, it is better to explicitly consider a morally relevant factor in the distribution than to accidentally end up with a distribution which happens to agree with what this factor implies (since the former but not the latter acknowledges the moral claims based on this factor). But in the context of historic responsibility for climate change, this idea speaks for an input-sensitive approach which adjusts the initial allocation for past emissions, since in Ohndorf et al.'s approach, historic responsibility is not explicitly considered at all while distributing (i.e. at the level of the initial allocation) - rather, the outcome (burdens induced) 
happens to correspond to historic responsibility (as long as current per capita-emissions correlate with past emissions). And this is ethically not on a par with explicitly considering historic responsibility while distributing.

These two arguments thus favor an input-sensitive approach: the proper place to account for historical responsibility is the initial allocation of emission rights, which implies departing from the equal per-capita rule. This is what we meant when we said: "WBGU seems to allocate equal emission rights for current people with too little regard for both, past injustices and overconsumption.” (emphasis added).

\section{The function of normative heuristics}

Now, one might be tempted to reply that by treating WBGUBA's equal per-capita approach as a proposal for a just distribution of the remaining budget, we have misunderstood its intention. Rather than being the true answer to the question of distributive justice, it is merely an approximation to that answer - "a simple, easy to calculate shortcut”, “a normative heuristic” (Ohndorf et al. 2015: 391).

First note that this maneuver changes the WBGUBA's justification - and thus its status - quite considerably. When the equal per-capita approach is understood as a normative heuristic, it is an easily calculated approximation to the distribution which would result, if we took into account the truly justice-determining features. This is a pragmatic, not an essentially ethical justification of basing climate policy on the equal per-capita allocation, and it amounts to a (partial) departure from the official policy addressed to policy-makers in WBGU (2009), where the rationale behind the percapita approach is presented as genuinely ethical: "From an ethical point of view, the best solution is to equally allocate emissions on a per-capita basis, so that national emissions budgets can be calculated according to the size of the population.” (WBGU 2009: 2). ${ }^{2}$

Second, approximations are a matter of degree. But when the stakes are as high as in climate change, we ought not to base policy advice on just any approximation. Rather, the approximation needs to be sufficiently good. So a normative heuristic is ethically acceptable only if it sufficiently well approximates the truly just distribution. But to assess whether the necessary condition is satisfied, we first have to come up with a reasonably sharp idea of how the truly just distribution looks like. ${ }^{3}$ This is the ethicists' domain; so introducing normative heuristics does not dispense of the need to first engage in ethics properly. And if we have done so and have this reasonably sharp

2 The departure is partial because later on (i.e. after the summary for policy-makers), the report is more cautious: "Based on the ethical principles outlined above, an allocation of equal per-capita emission allowances should be applied as a first approximation” (WBGU 2009: 22).

3 Perhaps we do not necessarily have to give a full specification of the truly just distribution; cp. Sen 2009. 
idea of how the truly just distribution looks like, why not use it as a distributive principle instead of the approximation? This poses a dilemma: Either we have no reasonably sharp idea of the truly just distribution; then Ohndorf et al. cannot claim that the suggested normative heuristic is a sufficiently good approximation, and the heuristic thus fails to be acceptable. Or we do have a reasonably sharp idea of the truly just distribution; then the heuristic is dispensable as an answer to the question of climate justice, and we should use that idea instead. ${ }^{4}$

Third, even if the normative heuristic approximates the just distribution sufficiently well, this does not silence our second objection to the input-insensitive approach : Distributing emission shares on the basis of a sufficiently good normative heuristic rather than on the basis of the truly relevant considerations is distributing the right way for the wrong reason. Since this is morally defective, we should not be content to answer questions of distributive justice based on normative heuristics alone. Instead, we should do ethics properly, sharpen our idea of a just distribution by identifying the truly relevant considerations, and base the distribution of emission shares upon these considerations.

4 A heuristic might still be useful for other reasons (e.g. due to its simplicity, it might avoid errors in application); but again, these are are reasons of a different (e.g. pragmatic) kind-, and not reasons of justice. We like to thank Dominic Roser for pointing this out. 


\section{References}

- Ohndorf M et al (2015): Emission budget approaches for burden sharing: Some thoughts from an environmental economics point of view. Clim Chang 133:385-395.

- Schuppert F \& Seidel C (2015): Equality, justice and feasibility: an ethical analysis of the WBGU's budget approach. Clim Chang 133:397-406.

- Sen (2009): The Idea of Justice. Belknap Press of Harvard University Press, Cambridge/MA.

- WBGU (2009) Solving the climate dilemma: The budget approach. Special Report. Berlin 